\title{
The Relative Corrosion Severity of Laboratory Environments on Mild Steel, Medium Carbon Steel, Brass and Aluminium
}

\author{
J. I. Sodiki
}

\begin{abstract}
By the measurement of weight changes with time, the extents of corrosion on specimens of mild steel, medium carbon steel, brass and aluminum exposed to the laboratory atmosphere and $0.1 \mathrm{M}$ solutions of sodium chloride, ammonium hydroxide and hydrochloric acid were obtained. These solutions, respectively, represent salt, basic and acid environments that are usually encountered by the test metals in actual service. Corrosion - time graphs were then drawn for each exposure environment to facilitate the assessment of the relative aggressiveness of each environment on the test metals. A graphical illustration was further made to show the relative aggressiveness of the environments on any particular metal.
\end{abstract}

Index Terms-Laboratory environments, mild steel, medium carbon steel, brass, aluminum.

\section{INTRODUCTION}

In selecting a metal for a specific application, it is necessary to have a prior knowledge of its corrosion behavior in the particular environment. In some other circumstances, it may also be required to have a knowledge of the relative aggressiveness of different environments on a particular service metal; or of the relative aggressiveness of a particular environment on different metals. Such knowledge is important, for instance, in a situation where alternative metal containers are being contemplated to hold a particular corrosive liquid.

In nearly neutral aqueous environments, the corrosion of metals is a result of the oxidation of the metal by a reaction which in its simplest form may be written as [1].

$$
M \rightleftarrows M^{2+}+2 e^{-}
$$

Assuming the metal to be bivalent as in the case of iron, copper and zinc; or as in the case of a trivalent metal such as aluminum.

$$
M \rightleftarrows M^{3+}+3 e^{-}
$$

It is well known that the susceptibility of a metal to electrochemical corrosion, to a large extent, depends on the metal's position in the electrochemical series; and when metals and their alloys are in service their relative corrosion behavior is usually predictable by recourse to the galvanic series relevant to the service environment. There is, thus, the

Manuscript received June 20, 2014; revised August 18, 2014.

J. I. Sodiki is with the Department of Mechanical Engineering at Rivers State University of Science and Technology, Port Harcourt, Nigeria (e-mail: jisodiki_partners@yahoo.com) galvanic series for sea water, for instance [2], [3].

While the galvanic series are useful in predicting the corrosion behavior of unprotected metals, several other factors come into play in determining actual corrosion patterns. Such factors include the metal's exact composition; its dimensional properties such as surface area, shape, and surface roughness index; and its surface temperature. The actual relative aggressiveness of different service environments on metals would therefore be known only through controlled experiments.

In this paper, the relative extent of corrosion, after any given time of exposure of specimens of mild steel, medium carbon steel, brass and aluminum, in particular laboratory environments are assessed. The environments utilized are the laboratory atmosphere and $0.1 \mathrm{M}$ solutions of sodium chloride, ammonium hydroxide and hydrochloric acid. These solutions respectively represent salt, basic and acid environments that are usually encountered by the test materials in actual service.

For the sake of achieving the desired control in experimentation, factors which normally influence the extent of corrosion over time such as the specimen's dimensions (i.e. length and diameter), surface roughness index and temperature were fixed. This was achieved by making the specimens as identical as possible and by placing them as close as possible on the same laboratory bench.

Such tests as these would be useful for other test metals and exposure environments.

\section{EXPERIMENTAL PROCEDURES}

\section{A. Test Material Composition}

The chemical composition of the test materials obtained from the stockist are as shown in Table I.

TABLE I: CHEMICAL COMPOSITION OF TEST MATERIAL

\begin{tabular}{|l|l|lr|}
\hline \multicolumn{1}{|c|}{ Test Material } & \multirow{2}{*}{ Main Element } & \multicolumn{2}{|c|}{$\begin{array}{c}\text { Composition of Other } \\
\text { Elements (Wt. \%) }\end{array}$} \\
\hline \multirow{4}{*}{ Mild steel } & \multirow{4}{*}{ Iron } & Carbon & 0.150 \\
& & Sulphur & 0.023 \\
& & $\begin{array}{l}\text { Phosphorus } \\
\text { Manganese }\end{array}$ & 0.030 \\
& & Silicon & 0.500 \\
& & Carbon & 0.250 \\
\hline \multirow{2}{*}{ Medium carbon } & \multirow{4}{*}{ Iron } & Sulphur & 0.350 \\
& & Phosphorus & 0.020 \\
& & Manganese & 0.035 \\
& & Silicon & 0.600 \\
Brass & Copper & Zinc & 0.170 \\
\hline \multirow{3}{*}{ Aluminium } & \multirow{2}{*}{ Aluminium } & Iron & 30 \\
& & Manganese & 0.7 \\
& & Silicon & 0.1 \\
& & & 0.5 \\
\hline
\end{tabular}




\section{B. Preparation of Exposure Environments}

Standard laboratory methods were used to prepare $0.1 \mathrm{M}$ solutions of sodium chloride, ammonium hydroxide and hydrochloric acid [4], [5].

\section{Preparation of Specimens}

Cylindrical dimensions of $60 \mathrm{~mm}$ length and $10 \mathrm{~mm}$ diameter were chosen for all specimens of the test metals. The specimens were obtained by turning on a 'Colchester Chipmaster' lathe. Each specimen was degreased by washing with a piece of cotton wool in acetone immediately after turning.

As it is well known that specimens with rough surfaces corrode faster than those with smooth ones $[6,7]$, specimens whose surface finish indices were as close as possible were chosen for exposure in each environment. This was ensured by measuring the surface finish index of each specimen with a 'Talysurf 10' sylus instrument, and sorting accordingly.

Each specimen was subsequently stored in a desiccator (which had been designated for each exposure environment) until the first weighing prior to exposure in the relevant environment.

\section{Corrosion Measurement}

Among the several methods that abound $[8,9,10,11]$, the method of weight change determination was chosen for the measurement of relative aggressiveness of the test environments. This was due to the ready availability of the required laboratory apparatus.

Some degree of flaking off and washing off of corrosion products was inevitable in the course of the measurements. This was more severe with the specimens exposed in the solutions than with those in the laboratory atmosphere. This necessitated careful handling of the specimens exposed to the laboratory atmosphere, to obtain periodic weighings of the same specimen. A corrosion - time graph was thus drawn for each specimen.

In the case of the specimens exposed in liquid environments successive weighings on the same specimen were not done. Rather, a set of specimens, as close as possible in surface finish index, was required to obtain a corrosion-time graph; the mean surface finish index being the representative one for the set. After the $0.1 \mathrm{M}$ solutions had been prepared and all the specimens had been prepared and sorted, the first weighings were done and the specimens exposed in the relevant environments.

\section{E. Exposure in Solution}

$75 \mathrm{ml}$ of the relevant solution were put in each of $75 \mathrm{ml}$ beakers which had been marked for identification. Each specimen was then immersed diagonally in the corresponding solution as shown in Fig. 1, and the time clock reading at the instant of immersion recorded. The top of the beaker was then covered with cardboard paper and the beaker rested on a table.

Subsequent clock readings and weighings were taken thereafter. Before any subsequent weighing, the specimen was washed in distilled water using a piece of cotton wool to scrub off any loose corrosion product. The used specimen was discarded after the weighing. The weight loss per unit surface area of specimen was thereby calculated for recorded times of exposure.

\section{F. Atmospheric Exposure}

For atmospheric exposure, the specimens were placed in a tray which could hold about 15 specimens at a time, as shown in Fig. 2. The wooden base support for the specimens was numbers, as shown, for easy identification.

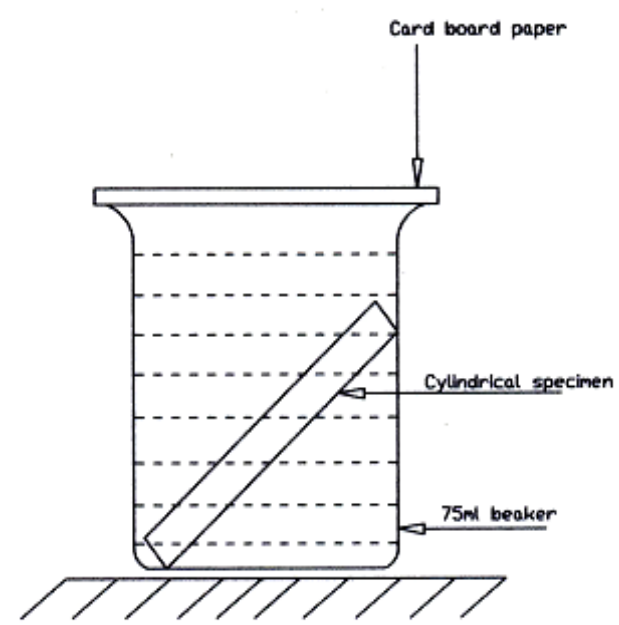

Fig. 1. Exposure in $01 \mathrm{M}$ solution.

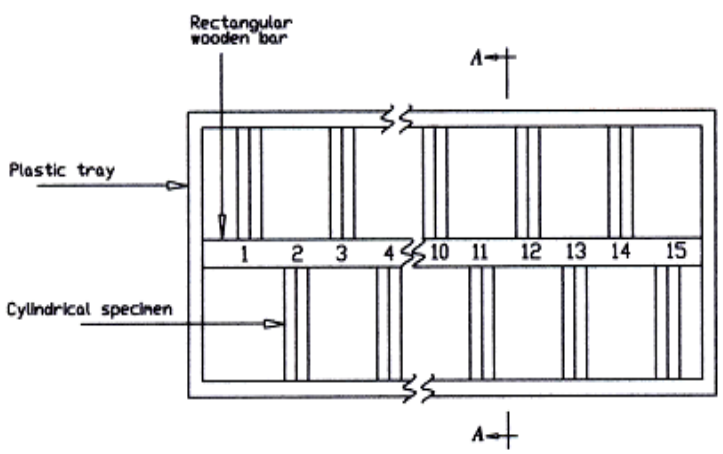

(a) Plan view of container.

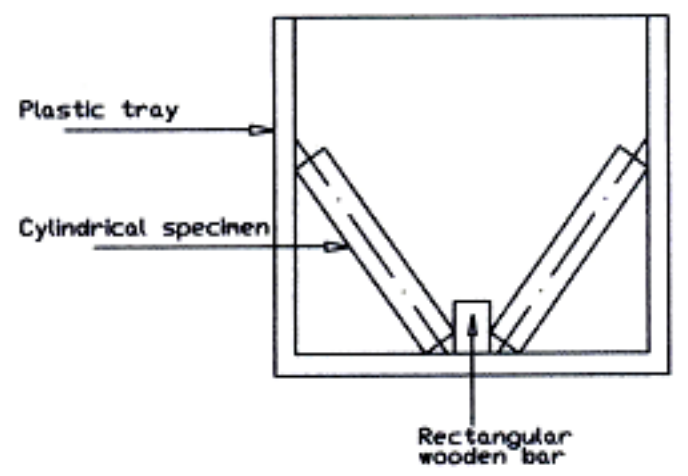

(b) View A-A.

Fig. 2. Atmospheric exposure.

\section{RESULTS}

Tables II to XVII show the results of the experiments. The results are also displayed as corrosion-time graphs in Figs. 3 to 7. Tables II to $\mathrm{V}$ show the results of the atmospheric exposure tests as weight increase per unit surface area of specimen; while Tables XI to XVII show the results of the tests for exposure in the solutions as weight loss per unit surface area. 
TABLE II: ATMOSPHERIC EXPOSURE OF MiLD STEEL (SURFACE FINISH VALUE $0.95 \mu \mathrm{M})$

\begin{tabular}{|ll|c|}
\hline \multicolumn{2}{|c|}{ Exposure Time } & $\begin{array}{c}\text { Weight Increase } \\
\left(10^{-3} \mathrm{mg} / \mathrm{mm}^{2}\right)\end{array}$ \\
\hline $77 \mathrm{~h}$ & $20 \mathrm{~min}$ & 3.706 \\
\hline $97 \mathrm{~h}$ & $20 \mathrm{~min}$ & 2.940 \\
\hline $118 \mathrm{~h}$ & $40 \mathrm{~min}$ & 4.340 \\
\hline $170 \mathrm{~h}$ & $0 \mathrm{~min}$ & 4.741 \\
\hline $240 \mathrm{~h}$ & $20 \mathrm{~min}$ & 6.043 \\
\hline $317 \mathrm{~h}$ & $48 \mathrm{~min}$ & 7.979 \\
\hline $340 \mathrm{~h}$ & $50 \mathrm{~min}$ & 7.779 \\
\hline
\end{tabular}

TABLE III: ATMOSPHERIC EXPOSURE OF MEDIUM CARBON STEEL (SURFACE FinISH VALUE $1.01 \mu \mathrm{M}$ )

\begin{tabular}{|ll|c|}
\hline \multicolumn{2}{|c|}{ Exposure Time } & $\begin{array}{c}\text { Weight Increase } \\
\left(10^{-3} \mathrm{mg} / \mathrm{mm}^{2}\right)\end{array}$ \\
\hline $44 \mathrm{~h}$ & $15 \mathrm{~min}$ & 0.318 \\
\hline $110 \mathrm{~h}$ & $21 \mathrm{~min}$ & 0.636 \\
\hline $163 \mathrm{~h}$ & $4 \mathrm{~min}$ & 0.636 \\
\hline $187 \mathrm{~h}$ & $39 \mathrm{~min}$ & 0.509 \\
\hline $255 \mathrm{~h}$ & $40 \mathrm{~min}$ & 0.573 \\
\hline $286 \mathrm{~h}$ & $6 \mathrm{~min}$ & 0.527 \\
\hline $318 \mathrm{~h}$ & $11 \mathrm{~min}$ & 0.730 \\
\hline
\end{tabular}

TABLE IV: ATMOSPHERIC EXPOSURE OF BRASS (SURFACE FINISH VALUE $1.01 \mu \mathrm{M})$

\begin{tabular}{|ll|c|}
\hline \multicolumn{2}{|c|}{ Exposure Time } & $\begin{array}{c}\text { Weight Increase } \\
\left(10^{-3} \mathrm{mg} / \mathrm{mm}^{2}\right)\end{array}$ \\
\hline $70 \mathrm{~h}$ & $16 \mathrm{~min}$ & 0.423 \\
\hline $105 \mathrm{~h}$ & $11 \mathrm{~min}$ & 0.446 \\
\hline $138 \mathrm{~h}$ & $12 \mathrm{~min}$ & 0.678 \\
\hline $191 \mathrm{~h}$ & $55 \mathrm{~min}$ & 0.593 \\
\hline $237 \mathrm{~h}$ & $56 \mathrm{~min}$ & 0.568 \\
\hline $301 \mathrm{~h}$ & $3 \mathrm{~min}$ & 0.689 \\
\hline
\end{tabular}

TABLE V: ATMOSPheric EXPosure OF ALUMinum (SURfACE Finish VALUE $1.10 \mu \mathrm{M})$

\begin{tabular}{|c|c|c|}
\hline \multicolumn{2}{|c|}{ Exposure Time } & Weight Increase \\
\hline $28 \mathrm{~h}$ & $57 \mathrm{~min}$ & 1.382 \\
\hline $46 \mathrm{~h}$ & $44 \mathrm{~min}$ & 1.682 \\
\hline $94 \mathrm{~h}$ & $4 \mathrm{~min}$ & 1.562 \\
\hline $122 \mathrm{~h}$ & $28 \mathrm{~min}$ & 2.223 \\
\hline $168 \mathrm{~h}$ & $25 \mathrm{~min}$ & 1.581 \\
\hline $216 \mathrm{~h}$ & $50 \mathrm{~min}$ & 2.068 \\
\hline $272 \mathrm{~h}$ & $41 \mathrm{~min}$ & 1.784 \\
\hline
\end{tabular}

TABLE VI: EXPOSURE OF MILD STEEL IN 0.1M HYDROCHLORIC ACID (SURFACE FINISH VALUe $1.17 \mu \mathrm{M}$ )

\begin{tabular}{|ll|c|}
\hline \multicolumn{2}{|c|}{ Exposure Time } & $\begin{array}{c}\text { Weight Loss } \\
\left(10^{-3} \mathrm{mg} / \mathrm{mm}^{2}\right)\end{array}$ \\
\hline $16 \mathrm{~h}$ & $35 \mathrm{~min}$ & 22.789 \\
\hline $45 \mathrm{~h}$ & $19 \mathrm{~min}$ & 51.989 \\
\hline $92 \mathrm{~h}$ & $44 \mathrm{~min}$ & 57.159 \\
\hline $111 \mathrm{~h}$ & $42 \mathrm{~min}$ & 56.036 \\
\hline $137 \mathrm{~h}$ & $26 \mathrm{~min}$ & 55.356 \\
\hline $164 \mathrm{~h}$ & $33 \mathrm{~min}$ & 56.604 \\
\hline $184 \mathrm{~h}$ & $20 \mathrm{~min}$ & 57.562 \\
\hline
\end{tabular}

TABLE VII: EXPOSURE OF MEDIUM CARBON STEEL IN 0.1 M HYDROCHLORIC ACID(SURFACE FINISH VALUE $1.10 \mu \mathrm{M}$ )

\begin{tabular}{|ll|c|}
\hline \multicolumn{2}{|c|}{ Exposure Time } & $\begin{array}{c}\text { Weight Loss } \\
\left(10^{-3} \mathrm{mg} / \mathrm{mm}^{2}\right)\end{array}$ \\
\hline $2 \mathrm{~h}$ & $1 \mathrm{~min}$ & 28.433 \\
\hline $22 \mathrm{~h}$ & $16 \mathrm{~min}$ & 45.646 \\
\hline $48 \mathrm{~h}$ & $42 \mathrm{~min}$ & 50.574 \\
\hline $73 \mathrm{~h}$ & $58 \mathrm{~min}$ & 51.408 \\
\hline $144 \mathrm{~h}$ & $53 \mathrm{~min}$ & 59.673 \\
\hline $192 \mathrm{~h}$ & $26 \mathrm{~min}$ & 64.302 \\
\hline $235 \mathrm{~h}$ & $46 \mathrm{~min}$ & 67.719 \\
\hline
\end{tabular}

TABLE VIII: EXPOSURE OF BRASS IN 0.1M HYDROCHLORIC ACID (SURFACE FINISH VALUE $1.20 \mu \mathrm{M}$ )

\begin{tabular}{|ll|c|}
\hline \multicolumn{2}{|c|}{ Exposure Time } & $\begin{array}{c}\text { Weight Loss } \\
\left(10^{-3} \mathrm{mg} / \mathrm{mm}^{2}\right)\end{array}$ \\
\hline $22 \mathrm{~h}$ & $48 \mathrm{~min}$ & 2.250 \\
\hline $69 \mathrm{~h}$ & $35 \mathrm{~min}$ & 6.897 \\
\hline $92 \mathrm{~h}$ & $48 \mathrm{~min}$ & 8.513 \\
\hline $118 \mathrm{~h}$ & $27 \mathrm{~min}$ & 10.825 \\
\hline $142 \mathrm{~h}$ & $14 \mathrm{~min}$ & 11.683 \\
\hline $191 \mathrm{~h}$ & $42 \mathrm{~min}$ & 16.508 \\
\hline
\end{tabular}

TABLE IX: EXPOSURE OF ALUMINUM IN 0.1 M HYDROCHLORIC ACID IN (SURFACE FINISH VALUE $1.16 \mu \mathrm{M}$ )

\begin{tabular}{|lc|c|}
\hline \multicolumn{2}{|c|}{ Exposure Time } & $\begin{array}{c}\text { Weight Loss } \\
\left(10^{-3} \mathrm{mg} / \mathrm{mm}^{2}\right)\end{array}$ \\
\hline $3 \mathrm{~h}$ & $59 \mathrm{~min}$ & 0.718 \\
\hline $28 \mathrm{~h}$ & $13 \mathrm{~min}$ & 1.618 \\
\hline $94 \mathrm{~h}$ & $32 \mathrm{~min}$ & 5.423 \\
\hline $117 \mathrm{~h}$ & $32 \mathrm{~min}$ & 6.636 \\
\hline $143 \mathrm{~h}$ & $38 \mathrm{~min}$ & 7.924 \\
\hline $194 \mathrm{~h}$ & $40 \mathrm{~min}$ & 9.893 \\
\hline $218 \mathrm{~h}$ & $4 \mathrm{~min}$ & 10.957 \\
\hline
\end{tabular}


TABLE X: EXPOSURE OF MILD STEEL IN 0.1M SODIUM CHLORIDE (SURFACE FinISH VALUE $1.09 \mu \mathrm{M}$ )

\begin{tabular}{|ll|c|}
\hline \multicolumn{2}{|c|}{ Exposure Time } & $\begin{array}{c}\text { Weight Loss } \\
\left(10^{-3} \mathrm{mg} / \mathrm{mm}^{2}\right)\end{array}$ \\
\hline $26 \mathrm{~h}$ & $9 \mathrm{~min}$ & 4.535 \\
\hline $96 \mathrm{~h}$ & $59 \mathrm{~min}$ & 4.502 \\
\hline $143 \mathrm{~h}$ & $15 \mathrm{~min}$ & 7.604 \\
\hline $169 \mathrm{~h}$ & $39 \mathrm{~min}$ & 8.334 \\
\hline $234 \mathrm{~h}$ & $22 \mathrm{~min}$ & 10.533 \\
\hline $263 \mathrm{~h}$ & $55 \mathrm{~min}$ & 11.290 \\
\hline $283 \mathrm{~h}$ & $29 \mathrm{~min}$ & 11.959 \\
\hline
\end{tabular}

TABLE XI: EXPOSURE OF MEDIUM CARBON STEEL IN 0.1 M SODIUM CHLORIDE (SURFACE FINISH VALUE $1.17 \mu \mathrm{M}$ )

\begin{tabular}{|ll|c|}
\hline \multicolumn{2}{|c|}{ Exposure Time } & $\begin{array}{c}\text { Weight Loss } \\
\left(10^{-3} \mathrm{mg} / \mathrm{mm}^{2}\right)\end{array}$ \\
\hline $23 \mathrm{~h}$ & $10 \mathrm{~min}$ & 5.050 \\
\hline $94 \mathrm{~h}$ & $10 \mathrm{~min}$ & 9.759 \\
\hline $117 \mathrm{~h}$ & $37 \mathrm{~min}$ & 13.588 \\
\hline $168 \mathrm{~h}$ & $40 \mathrm{~min}$ & 16.223 \\
\hline $186 \mathrm{~h}$ & $30 \mathrm{~min}$ & 18.318 \\
\hline $232 \mathrm{~h}$ & $56 \mathrm{~min}$ & 22.675 \\
\hline $281 \mathrm{~h}$ & $22 \mathrm{~min}$ & 26.328 \\
\hline
\end{tabular}

TABLE XII: EXPOSURE OF BRASS IN 0.1M SODIUM CHLORIDE (SURFACE FinISH VALUE $1.05 \mu \mathrm{M}$ )

\begin{tabular}{|ll|c|}
\hline \multicolumn{2}{|c|}{ Exposure Time } & $\begin{array}{c}\text { Weight Loss } \\
\left(10^{-3} \mathrm{mg} / \mathrm{mm}^{2}\right)\end{array}$ \\
\hline $21 \mathrm{~h}$ & $27 \mathrm{~min}$ & 0.307 \\
\hline $68 \mathrm{~h}$ & $17 \mathrm{~min}$ & 0.893 \\
\hline $91 \mathrm{~h}$ & $28 \mathrm{~min}$ & 1.250 \\
\hline $124 \mathrm{~h}$ & $9 \mathrm{~min}$ & 1.429 \\
\hline $142 \mathrm{~h}$ & $6 \mathrm{~min}$ & 1.421 \\
\hline $189 \mathrm{~h}$ & $28 \mathrm{~min}$ & 1.440 \\
\hline $240 \mathrm{~h}$ & $47 \mathrm{~min}$ & 1.428 \\
\hline
\end{tabular}

TABLE XIII: EXPOSURE OF ALUMINUM IN 0.1M SODIUM CHLORIDE (SURFACE Finish VALUE $1.13 \mu \mathrm{M}$ )

\begin{tabular}{|ll|c|}
\hline \multicolumn{2}{|c|}{ Exposure Time } & $\begin{array}{c}\text { Weight Loss } \\
\left(10^{-3} \mathrm{mg} / \mathrm{mm}^{2}\right)\end{array}$ \\
\hline $39 \mathrm{~h}$ & $28 \mathrm{~min}$ & 0.268 \\
\hline $73 \mathrm{~h}$ & $2 \mathrm{~min}$ & 0.536 \\
\hline $104 \mathrm{~h}$ & $36 \mathrm{~min}$ & 0.804 \\
\hline $163 \mathrm{~h}$ & $49 \mathrm{~min}$ & 0.892 \\
\hline $223 \mathrm{~h}$ & $2 \mathrm{~min}$ & 0.890 \\
\hline $260 \mathrm{~h}$ & $32 \mathrm{~min}$ & 1.250 \\
\hline
\end{tabular}

TABLE XIV: EXPOSURE OF MILD STEEL IN 0.1M AMMONIUM HYDROXIDE (SURFACE FINISH VALUE $1.21 \mu \mathrm{M}$ )

\begin{tabular}{|ll|c|}
\hline \multicolumn{2}{|c|}{ Exposure Time } & $\begin{array}{c}\text { Weight Loss } \\
\left(10^{-3} \mathrm{mg} / \mathrm{mm}^{2}\right)\end{array}$ \\
\hline $25 \mathrm{~h}$ & $26 \mathrm{~min}$ & 0.876 \\
\hline $75 \mathrm{~h}$ & $50 \mathrm{~min}$ & 6.152 \\
\hline $125 \mathrm{~h}$ & $21 \mathrm{~min}$ & 10.133 \\
\hline $165 \mathrm{~h}$ & $18 \mathrm{~min}$ & 13.741 \\
\hline $194 \mathrm{~h}$ & $51 \mathrm{~min}$ & 15.597 \\
\hline $289 \mathrm{~h}$ & $33 \mathrm{~min}$ & 23.892 \\
\hline $312 \mathrm{~h}$ & $34 \mathrm{~min}$ & 26.462 \\
\hline
\end{tabular}

TABLE XV: EXPoSURE OF MEDIUM CARBon STEEL IN $0.1 \mathrm{M}$ AMMONIUM HYDROXIDE (SURFACE FINISH VALUE $1.24 \mu \mathrm{M}$ )

\begin{tabular}{|ll|c|}
\hline \multicolumn{2}{|c|}{ Exposure Time } & $\begin{array}{c}\text { Weight Loss } \\
\left(10^{-3} \mathrm{mg} / \mathrm{mm}^{2}\right)\end{array}$ \\
\hline $15 \mathrm{~h}$ & $36 \mathrm{~min}$ & 1.139 \\
\hline $44 \mathrm{~h}$ & $32 \mathrm{~min}$ & 4.050 \\
\hline $110 \mathrm{~h}$ & $40 \mathrm{~min}$ & 8.814 \\
\hline $139 \mathrm{~h}$ & $13 \mathrm{~min}$ & 12.534 \\
\hline $162 \mathrm{~h}$ & $48 \mathrm{~min}$ & 15.775 \\
\hline $187 \mathrm{~h}$ & $51 \mathrm{~min}$ & 16.984 \\
\hline $208 \mathrm{~h}$ & $54 \mathrm{~min}$ & 18.915 \\
\hline $259 \mathrm{~h}$ & $33 \mathrm{~min}$ & 24.020 \\
\hline
\end{tabular}

TABLE XVI: EXPOSURE OF BRASS IN 0.1M AMMONIUM HYDROXIDE (SURFACE FINISH VALUE $1.15 \mu \mathrm{M}$ )

\begin{tabular}{|ll|c|}
\hline \multicolumn{2}{|c|}{ Exposure Time } & $\begin{array}{c}\text { Weight Loss } \\
\left(10^{-3} \mathrm{mg} / \mathrm{mm}^{2}\right)\end{array}$ \\
\hline $21 \mathrm{~h}$ & $19 \mathrm{~min}$ & 0.261 \\
\hline $67 \mathrm{~h}$ & $59 \mathrm{~min}$ & 0.894 \\
\hline $91 \mathrm{~h}$ & $13 \mathrm{~min}$ & 0.898 \\
\hline $116 \mathrm{~h}$ & $51 \mathrm{~min}$ & 0.983 \\
\hline $140 \mathrm{~h}$ & $10 \mathrm{~min}$ & 0.947 \\
\hline $255 \mathrm{~h}$ & $6 \mathrm{~min}$ & 0.982 \\
\hline
\end{tabular}

TABLE XVII: EXPOSURE OF ALUMINUM IN 0.1M EXPOSURE OF ALUMINUM IN 0.1M (SURFACE FINISH VALUE $1.09 \mu \mathrm{M}$ )

\begin{tabular}{|ll|c|}
\hline \multicolumn{2}{|c|}{ Exposure Time } & $\begin{array}{c}\text { Weight Loss } \\
\left(10^{-3} \mathrm{mg} / \mathrm{mm}^{2}\right)\end{array}$ \\
\hline $25 \mathrm{~h}$ & $53 \mathrm{~min}$ & 0.334 \\
\hline $76 \mathrm{~h}$ & $2 \mathrm{~min}$ & 0.121 \\
\hline $125 \mathrm{~h}$ & $31 \mathrm{~min}$ & 0.569 \\
\hline $146 \mathrm{~h}$ & $17 \mathrm{~min}$ & 0.412 \\
\hline $217 \mathrm{~h}$ & $11 \mathrm{~min}$ & 0.360 \\
\hline $283 \mathrm{~h}$ & $46 \mathrm{~min}$ & 0.714 \\
\hline
\end{tabular}




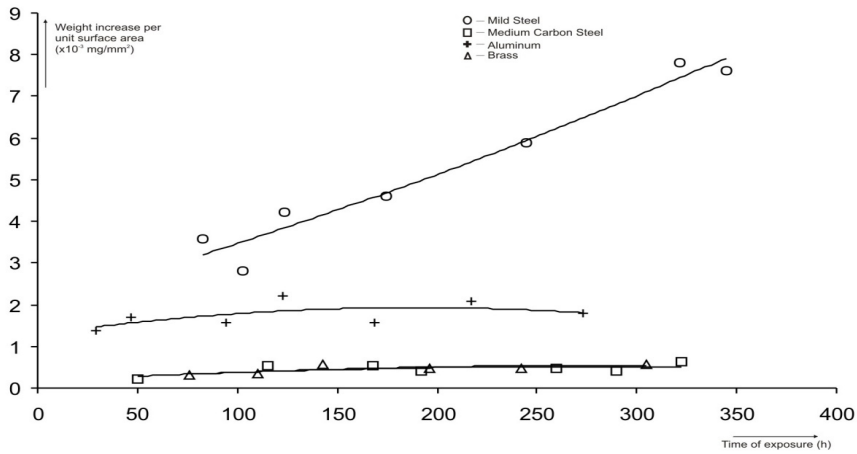

Fig. 3. Corrosion-time graphs of test metals in the laboratory atmosphere.

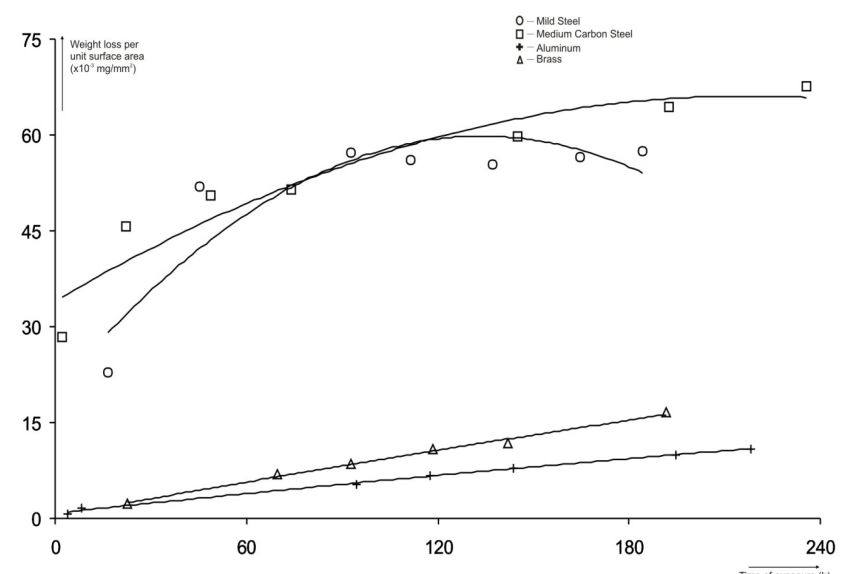

Fig. 4. Corrosion-time graphs of test metals in $0.1 \mathrm{M}$ hydrochloric acid.

\section{DisCUSSION OF RESULTS}

\section{A. Corrosion - Time Behaviour}

Graphically, all the test materials show a general trend of increasing extent of corrosion with time of exposure, within the limits of exposure time utilized. There is also a general trend of decreasing slope, indicative of reducing corrosion rate, as time passed. This is expected as the initial corrosion products usually provide some surface protection against further attack. Another contributing factor to this trend, in the case of exposure in the $0.1 \mathrm{M}$ solutions, is the progressive reduction of the concentrations of the reactant constituents in the solutions. Such a reduction in concentration is not anticipated in the atmospheric tests as the laboratory atmosphere can be regarded to be of infinite extent.

However, some of the specimens and environments show almost constant slopes of the corrosion-time graphs due to the short exposure times utilized, in which the surface protection effect and the weakness of the exposure environments are not yet noticed.

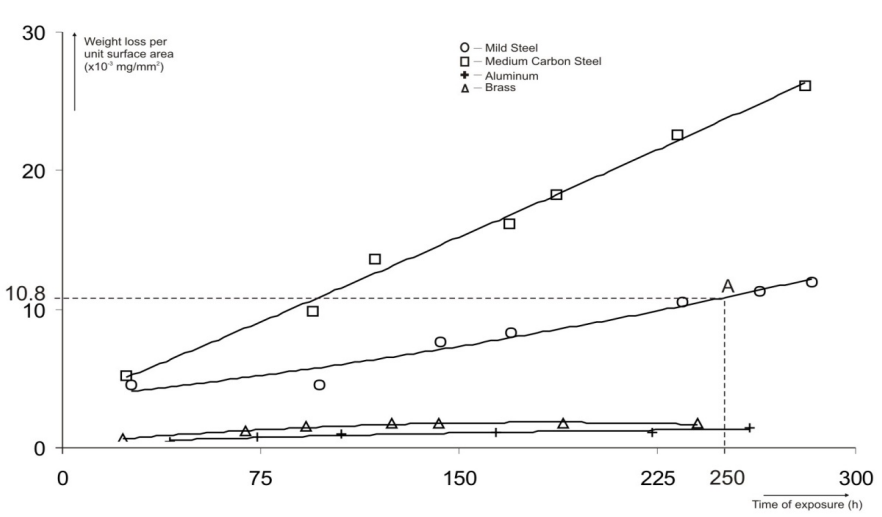

Fig. 5. Corrosion-time graphs of test metals in $0.1 \mathrm{M}$ sodium chloride.

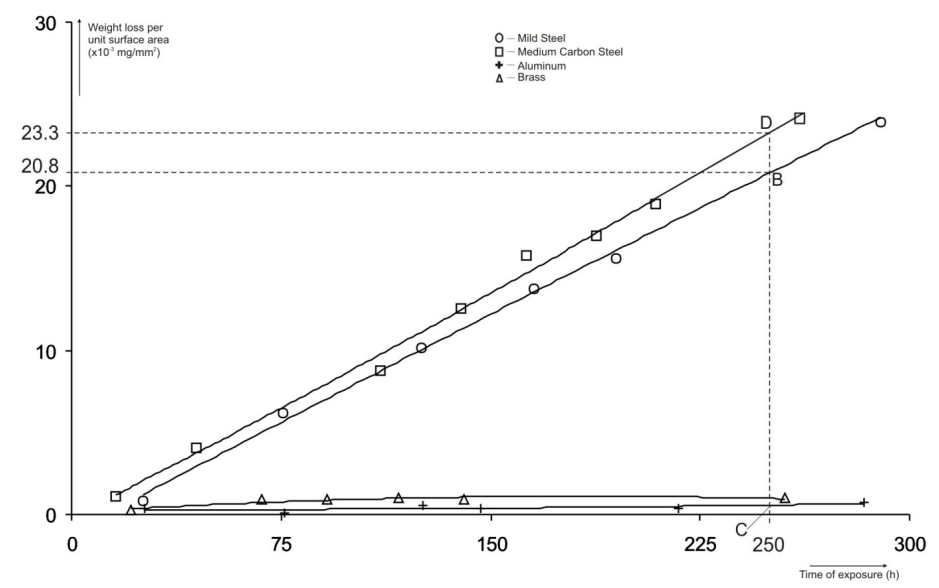

Fig. 6. Corrosion-time graphs of test metals in $0.1 \mathrm{M}$ ammonium hydroxide.

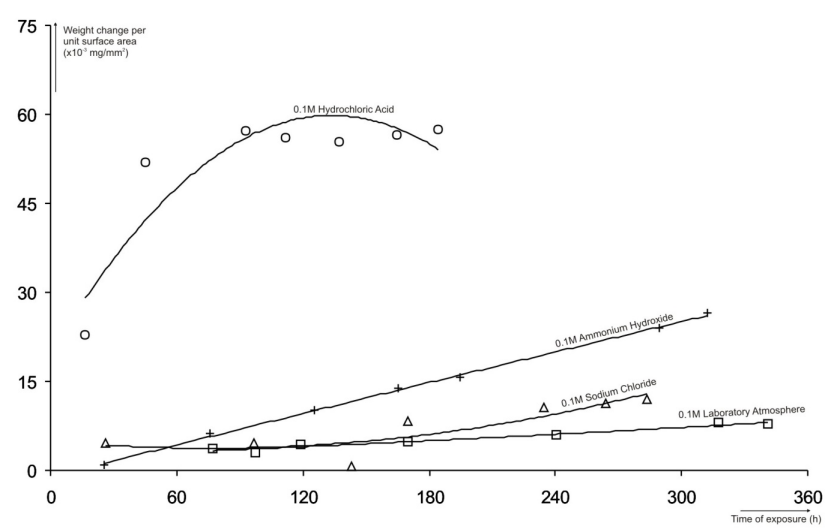

Fig. 7. Corrosion-time graphs of mild steel in different environments.

\section{B. Atmospheric Exposure}

The corrosion action of the laboratory atmosphere on medium carbon steel and brass are equal in severity, within the limits of exposure time utilized, as the graphs of both metals coincide. The general trend is an increasing order on medium carbon steel (and brass), aluminium, and mild steel.

\section{Exposure in 0.1M Hydrochloric Acid}

Within the period of $100 \mathrm{~h}$ and $120 \mathrm{~h}$ the attack of $0.1 \mathrm{M}$ hydrochloric acid on mild steel and medium carbon steel appear to be equally aggressive. However, outside of this period, medium carbon steel becomes more severely attacked than mild steel. The severity of attack on the test metals follows a general increasing order of aluminium, brass, mild steel and medium carbon steel.

\section{Exposure in 0.1M Sodium Chloride}

The severity of attack of $0.1 \mathrm{M}$ sodium chloride on the test metals is in an increasing order of aluminium, brass, mild steel and medium carbon steel; as in the case of hydrochloric acid. However, the severity of attack (as observed from the weight loss values) for all the specimens is less for sodium chloride than for hydrochloric acid.

\section{E. Exposure in 0.1M Ammonium Hydroxide}

The general order of severity of attack on the test metals by this environment is the same as for $0.1 \mathrm{M}$ hydrochloric acid and $0.1 \mathrm{~m}$ sodium chloride. Furthermore, for all exposure times, the order of magnitude of weight loss in $0.1 \mathrm{M}$ ammonium hydroxide is quite close to that in $0.1 \mathrm{M}$ sodium chloride, for all the test metals; except mild steel whose extent of corrosion is generally higher in $0.1 \mathrm{M}$ ammonium hydroxide than in $0.1 \mathrm{M}$ sodium chloride. 


\section{F. Experimental Constraints}

As noted in an earlier paper which investigated the effect of surface finish on the extent of corrosion of mild steel, using a similar experimental set-up [2], possible experimental shortcomings include the following:

- The test materials are assumed to be homogenous and of standard composition. However, the inevitable heterogeneity of composition of the test materials could bring about unexpected corrosion patterns.

- For tests wherein weight increases were measured (i.e. the atmospheric exposure tests), flaking off of corrosion products from the metal surface in the course of the experiments might erroneously lower subsequent weight readings.

- Although weight changes have been presented in terms of unit surface area of specimen, there could have been discrepancies due to unequal dimensions within a set of specimens. This has arisen due to the difficulty in obtaining equal dimensions during machining.

- Due to the shortness in available exposure times resulting in a few numbers of points, many of the graphs only show approximate trends.

\section{CONCLUSIONS}

Within the limits of values utilized in the experiments, the following conclusions can be made:

- The test metals show a general increasing severity of corrosion (given as weight change per unit surface area) and decreasing corrosion rates (given as the slopes of the corrosion-time graphs) with increasing exposure times.

- The atmosphere exposure tests indicate an increasing severity of corrosion in the order of medium carbon steel and brass (whose graphs coincide), aluminium and mild steel; while for exposure in each of the $0.1 \mathrm{M}$ solutions there is a general severity increase in the order of aluminum, brass, mild steel and medium carbon steel.

- The test can be used to compare the aggressiveness of different environments on a given metal. Thus, after $250 \mathrm{~h}$, while the mild steel specimens corrode to an extent of only $10.8 \times 10^{-3} \mathrm{mg} / \mathrm{mm}^{2}$ weight loss in $0.1 \mathrm{M}$ sodium chloride, they corrode to an extent of $20.8 \mathrm{x}$ $10^{-3} \mathrm{mg} / \mathrm{mm}^{2}$ in $0.1 \mathrm{M}$ ammonium hydroxide. (See points A and B in Figs. 5 and 6, respectively). Fig. 7 shows the relative aggressiveness of different environments on mild steel, as an example of such comparisons. Such comparisons aid material selection for engineering applications.

- Furthermore, the corrosion severity of a particular

environment on different metals can be compared. If, for instance, it is intended to contain an ammonium hydroxide solution, this study indicates the preference for an aluminium container over one of steel. This is because while after about $250 \mathrm{~h}$ the aluminium container would remain practically unattached, a medium carbon steel container would have corroded by $23.3 \times 10^{-3} \mathrm{mg} / \mathrm{mm}^{2}$ weight loss. (See points C and D in Fig. 6).

As many metals are usually exposed in fluid environments under flow conditions, suitable experiments can be done under such conditions. Such experiments would, for instance, indicate suitable metals and alloys for the piping of different fluids.

\section{REFERENCES}

[1] Oxidation-Reduction Reactions. [Online]. Available: http://www.iit.edu/arc/workshops/pdfs/Redox_Rxns.pdf

[2] Galvanic Series. [Online]. http://www.en.wikipedia.org/wiki/Galvanic_series

[3] Galvanic Series. [Online].

[4] How to Make Standard Solutions for Chemistry.[Online]. Available: http://www.scn.org/ bh162/making molar \& normal solutions.pdf

[5] Laboratory Solution Preparation. [Online]. Available: http://www.inside.bard.edu/ bjude/resources/Lab-SolutionPreparation-Guide-1.pdf

[6] H. H. Uhlig, Corrosion Handbook, New York: John Wiley and Sons, 1948, p. 15

[7] J. I. Sodiki, "A fine surface finish would elongate the life span of mild steel for service in the petroleum industry," in Proc. the Nigerian Metallurgical Society, pp.19-25, Port Harcourt, 1993.

[8] W. H. Ailor, Handbook of Corrosion Testing and Evaluation, New York: John Wiley and Sons, 1971, pp. 5-103

[9] F. A. Champion, Corrosion Testing Procedures, London: Chapman and Hall, 1964, pp. 2-62

[10] Corrosion and Corrosion Measurement, Newsletter No. 3, RMS Foundation, Bettlach, Switzerland, 2013

[11] T. J Tan, B. Kinsella, and S. Bailey, "An experimental comparison of corrosion rate measurement techniques: weight loss measurement, linear polarization, electrochemical impedance, spectroscopy and electrochemical noise analysis," presented at the Australian Corrosion Association Conference, Perth, November 12-15, 1995

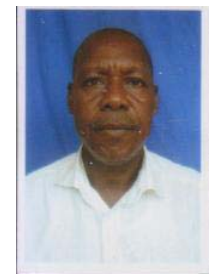

control.
J. I. Sodiki received his B.Sc. degree in mechanical engineering from University of Lagos, Nigeria in 1981 and M.Sc. degree in mechanical engineering from University of Lagos in 1986. He is working as a lecturer in Department of Mechanical Engineering at Rivers State University of Science and Technology, Port Harcourt, Nigeria. He has 19 years of teaching experience at university level. His areas of interest include thermo-fluids, building services, and corrosion 